\title{
An Augmented Reality Approach to Integrate Practical Activities in E-Learning Systems
}

\author{
EL KABTANE Hamada \\ Faculty Semlalia \\ University Cadi Ayyad, \\ Marrakesh, Morocco \\ EL ADNANI Mohamed \\ Faculty Semlalia \\ University Cadi Ayyad, \\ Marrakesh, Morocco
}

\author{
SADGAL Mohamed \\ Faculty Semlalia \\ University Cadi Ayyad, \\ Marrakesh, Morocco \\ MOURDI Youssef \\ Faculty Semlalia \\ University Cadi Ayyad, \\ Marrakech, Morocco
}

\begin{abstract}
In the past, the term E-learning was mentioned to any learning method that used electronic machine for the distribution. With the evolution and the apparition of the internet, the term e learning has been evolved and referred to the online courses. There are a lot of platform which serves to distribute and manage the learning content. In some domain learners need to use some equipment and useful product for purpose completing the image built in the theoretical part by the practical activity part. However, most of those platforms suffer from a lack in tools that offer practical activities for learners. Using videos, virtual laboratories or distance control of real equipment as solutions to solve this lack were proposed but still limited. The mixed reality as new technology promised to create a virtual environment where the learner is an actor and can interact with the virtual objects. This article present an approach for developing integrated E-learning systems, helping to carry out the practical work by establishing a virtual laboratory that all tools and products can be manipulated by learners and teachers like in real practical activity, based on an augmented reality system.
\end{abstract}

Keywords-E-learning; virtual reality; augmented reality; practical activities

\section{INTRODUCTION}

With the apparition of E-learning, a wide window has been opened to solve several problems such as the availability of media, team-learning and collaborative learning at different geographical positions without the need to travel.

The Virtual Learning Environment (VLE), not only provides rich teaching models and learning content, but also helps improve the ability of students to analyze problems and explore new concepts [1]. With the VLE, learning content has become interactive and the learner can make a self-evolution during his studies, allowing him to know his progress in a simple, sophisticated and precise way. The teacher, in turn, can follow each learner and controls his level since the platform.

However, E-learning suffer from a lack, especially in some domains, like Engineering, where learners need materials and useful products for a good training and keep learners' motivation and creativity.
In education, learners' creativity can be fostered in six different facets [2][3]:

1) Self-reflective learning

2) Independent learning

3) Curiosity and motivation

4) Multi-perspective thinking

5) Reach for original ideas

6) Learning by doing

A small study indicates that especially the facets 2,5 , and 6 might be fostered insufficiently in education[4].So the use of laboratories in Education, - e.g. in material sciences, offer the opportunity to implement experiential and research. Within these laboratories, the learners have the chance to realize their own experiments and build their experiences in their learning processes. According to [5], there is a tiny enough open space for learners to work creatively with the course content and get in contact with real technical equipment. This is due to the availability and the cost of equipment, limited equipment resources, the availability of the environment of the experimentation and safety of the learners against the dangers they may come from experimentation (nuclear, chemical, etc.).

Many tools have been proposed as a technological breakthrough that has the power to facilitate the implementation of practical activities in education. Like the PeTEX project done by universities in Dortmund (Germany), Palermo (Italy) and Stockholm (Sweden) - implemented an opportunity to do experiential learning by using real laboratory equipment without being physically in the laboratory but having access via the internet [6]. Same for [7] who proposed "Tele-TP" as a solution that involves making a distance manipulation by remote control real instruments and synchronous telemetry. The use of real instruments and equipment consists maintenance all the time and its maintenance may require significant human and material resources.

The Augmented Reality and Virtual Reality are promised to be a new technology to develop Virtual Environments where the learner interacts with virtual objects. There are many other classes of Augmented Reality (AR) and Virtual Reality (VR) 
applications, such as medical visualization, entertainment, advertising, maintenance and repair, annotation, robot path planning [8]. Research and Application of Mixed Reality (MR) technology in education have enriched the form of teaching and learning in the current strategy in education[9].The marriage between AR/VR; the MR in VLE allows performing experiments that are up to now expensive and sometimes impossible in the real world.

An architecture integrating virtual learning environments in an adaptive e-learning system is proposed. eMouss@ide is a self-correcting adaptive learning system, offering learning scenarios based on the learners' learning styles and has the ability to self-correct based on traces and learners' feedback. The authors propose an upgrade to eMouss@ide platform that ensures the distance practical activities. The model uses the Augmented Reality (AR) techniques to present a complete course with practical aspect. The realization of such a system aspires to the completion of some activities in a virtual way like the practical work in distance learning courses or in highrisk environments (experiments in the presence of chemical or nuclear products,...) and it can economize on tools.

The rest of the paper is organized as follows: the second section presents a state of art; adaptive E-learning, Virtual Learning Environment (VLE) and Mixed Reality (MR) and Experimentation in E-learning. The Third section describes the proposal. In the fourth part outlines the results and the feedback of teachers and learners. Ultimately, the fifth section is dedicated to the conclusion.

\section{LITERATURE REVIEW}

\section{A. Adaptation of E-learning}

An E-learning system is a communication platform that permits learners to reach several learning tools, like document sharing systems, discussion boards, content repositories and assessments, without limitations of time and place[10]. Students have individual learning style preferences including: visual learners (V: they Learn from videos, pictures, graphs, charts and flow diagrams and schemas), auditory (A: they learn from speeches, they are a good listeners and they prefer to talk about what they learn) and kinesthetic (K: they learn from touch, hearing, smell, taste, sight also they tend to have the possibility to move, do experiments, go on excursions to live the experience, to examine and to manipulate the material) [11].

The internet represents an important source of information for learners, considering the number of information which offer on a specific domain that the learner can exploit freely, in one hand that make the utilization of internet in E-learning is very profitable [12].Especially after the apparition of the Web 2.0 and his tools such as podcasts, wikis and blogs, the diffusion of the information becomes easier and the e-learning has become more popular, but in other hand it can be a bad reference, because not any information is not credible also the large volume of information with a lack of supervision led the learner to a knowledge overlapping. Therefore, the organization of information according to the learner's needs is so important; here it comes the Adaptive Hypermedia Systems
(AHS). Adaptive Hypermedia was presented as one of solution[13], especially where learners use an e-learning system without assistance from a physical tutor (teacher) who can ensure the adaptivity in the classroom. It offers a new functionality to the hypermedia systems by giving the users the possibility to consult smartly the content of the hyperspace. AHSs' objective is to adapt the user interface and the content and the navigational type [14]. The hypermedia system is adapted according to the user's knowledge, experience, knowledge background, preferences and his/her intentions [15][16].

There are a lot of adaptive educational hypermedia systems developed since 1996 [17] such as InterBook [18],ELM-ART [19], 2L670 [20], TANGOW[21], AHA! [22], INSPIRE [23] etc. The general architecture which they base these systems can be simplified to a learner model, a content model and an adaptation strategy, according to [24] (Fig. 1).

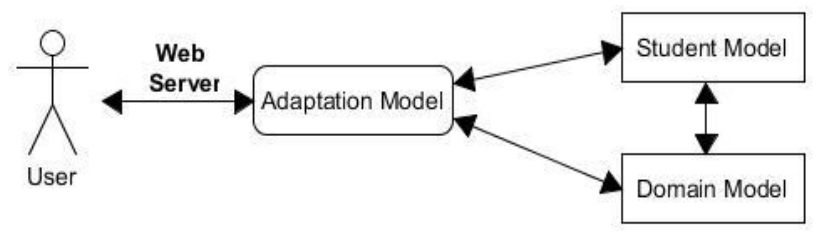

Fig. 1. The general architecture of an adaptive educational system

\section{B. V irtual Learning Environment (VLE) and Mixed Reality (MR)}

\section{1) Virtual Learning Environment}

It was noticed that the existence of the internet and the multimedia tools could be used to construct and build a new environment for education, called the Virtual Learning Environment (VLE). In this environment, learners and teachers are not obliged to be present at the same time or in a specified location (Classroom), unlike in the regular classroom environment, even if the teacher uses advanced technologies, still the limitation of the learners who must adapt to the location and time constraints of the course.

The Virtual Learning Environment (VLE) not only provides rich templates and various teaching learning content, but also helps improve the ability to analyze problems and explore new concepts of the learner. Integrated with immersive benefits, interactive and "imaginational" it built a shareable virtual learning space that all learners involved in the virtual community can access.

The VLE has the tools that administrators, teachers and learners need to realize their tasks. The students are given tests at specified times, and answers to the questions are transmitted to the teacher automatically [25]. With the VLE, learning content has become interactive and the learner can make a selfevolution during his/her studies, allowing, the learner, to follow his/her progress in the E-learning in a simple, sophisticated and precise way. The teacher, in turn, can follow each learner and controls his level since the platform. The VLE allows performing experiments that are up to now expensive and sometimes impossible in the real world [26]. 
Three of the most used open source VLE are DotLRN ${ }^{1}$, Moodle $^{2}$ and Sakai ${ }^{3}$. DotLRN as an "adopted enterprise-class open source software for supporting e-learning and digital communities" for "supporting e-learning and digital communities", Moodle defines itself as an "Open source software package designed using sound pedagogical principles, to help educators create effective online learning communities" and Sakai as an "Open source software freely available, feature-rich technology solution for learning, teaching, research and collaboration".

\section{2) Augmented reality and Virtual reality}

On the Reality-Virtuality continuum by Milgram [27] (Fig.2), the AR is one part of the area of Mixed Reality. The AR system consists of adding virtual objects in a real-world environment. The Augmented Reality is an emerging technology with which a person can see more than others see, hear more than others hear and perhaps even touch, smell and taste things that others cannot[28]. According to [29],there is three characteristics must be integrated into an AR interface: the combination of the real and the virtual, the feasibility in three dimensions and real time interaction.

Several remarkable exists regarding the definition of Virtual Reality. This paper uses a definition of VR proposed by [30]; VR is defined as the use of a computer-generated 3D environment - called a "virtual environment" (VE) - that one can navigate and interact with, resulting in real-time simulation of one or more of the user's five senses. "Navigate" refers to the ability to move around and explore the VE, and "interact" refers to the ability to select and move objects within the VE.

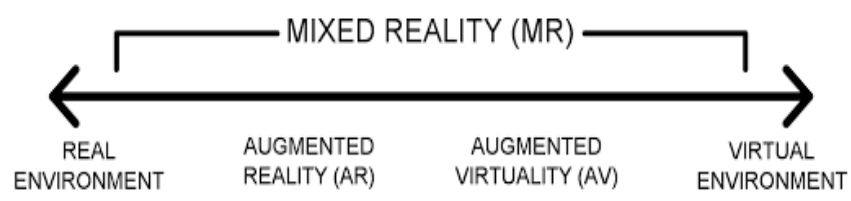

Fig. 2. Virtuality continuum (Milgram)

Augmented reality and virtual reality share some common characteristics such as interaction, immersion and navigation [31][32]. These characteristics can be derived from Azuma's AR properties. As $\mathrm{AR}$ and VR technologies continue to advance, the possibilities for using AR and VR within several sectors growing and they have already found their place in many different domains like medicine, advertising, military, entertainment, manufacturing, education, as well as many others[33].

According to [34], several researchers have suggested that learners can improve their knowledge and enhance their motivation to learn with virtual and augmented reality. The usage of AR in education began since [35] created the Magic Book, where he uses a normal book as the main interface for objects and user can read the text normally (Fig. 3).
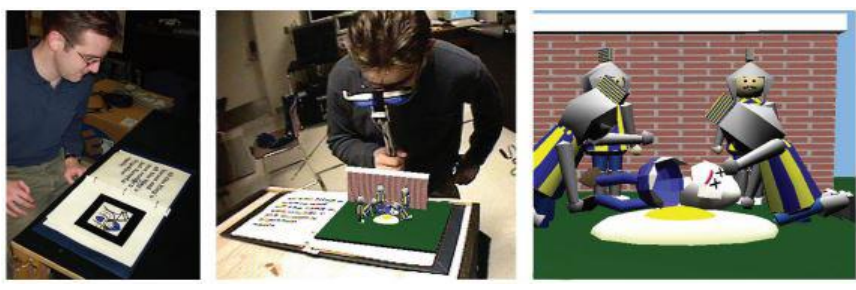

Fig. 3. Using the MagicBook interface to move between reality and virtual reality [37]

\section{Actual systems for practical activities in E-learning}

Klob stats and explained the meaning of the "learning" by: "Learning is the process whereby knowledge is created through the transformation of experience" [36]. "The use of laboratories is essential for the education in engineering and science related fields at a high qualitative level. Laboratories allow the application and testing of theoretical knowledge in practical learning situations. Active working with experiments and problem solving does help learners to acquire applicable knowledge that can be used in practical situations. That is why courses in the sciences and engineering incorporate laboratory experimentation as an essential part of educating students" [37].

At present, several solutions are implemented for research and educational activity:

As solution, the use of videos that were filmed and showed the unfolding of the practical activity, allow students to see the sequences in motion and to listen to the narration. The major limit of this solution is the luck of interactivity, the learner still passive, cannot interact with the objects [29] and just watch the video.

The use of real equipment remotely, [6] proposed PeTEX project (Fig.4) and [7] proposed "Tele-TP". They have the same principle; offer the opportunity to do experimentation and use real instruments without being present physically in the laboratory, the learner just need access via the internet. E.g. Engineering students once they graduated will work with real technical equipment to solve real problems; those systems offer this contact with real materials remotely via internet. The main limits of this solution are the learner or the user needs internet to connect to system and if it happened and the user lose internet, there is risk that he lose his unsaved data. The use of real equipment always costly and the installation of the system is an additional investment in the purchase. The probability that the equipment break down is high, thus the laboratory equipment may need a periodic calibration, also require a lot of maintenance and it is necessary to prevent any distance contact by the users until the technicians finish the maintenance or the calibration. The maintenance may consists significant human and material resources and often takes time to restore the functioning of the system. 


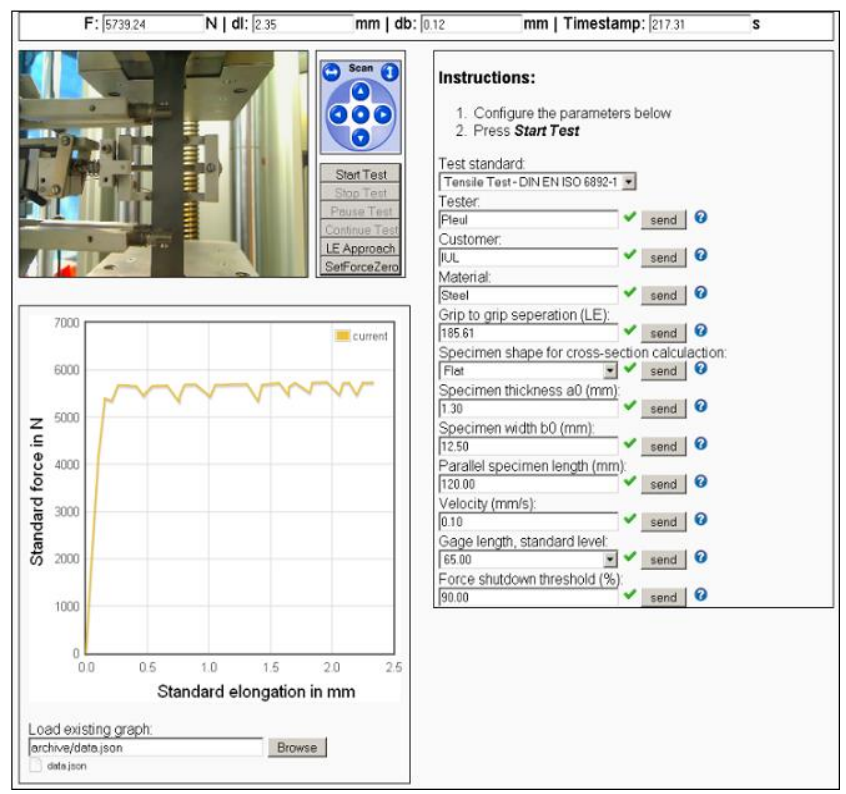

Fig. 4. Interface of tele-operated Tensile Test [6]

Another solution proposed aimed to resolve the limits of the previous solution, is by the use of Virtual Laboratories. VMSLab-G [38] use virtual reality approaches to describe chemical experiments at both human and molecular level (Fig.5). The user can walk-by and enter the rooms. In this way, one can get in contact with the experimental setup, use the various components and follow a given protocol by driving the mouse and activating the relevant sensors. This solution solve the problem of using real material because all the equipment are virtual also the user is safe, but the main limits of this solution are the user needs internet, for connecting to system. If the connection is lost, the user may lose the unsaved data. The lack of virtual equipment setup experience and of hands on debugging experience and trouble shooting. Those virtual laboratories have a license limit to how many users can run simultaneously. In addition, the user still confined to using the keyboard, the mouse and sometimes joysticks [39].

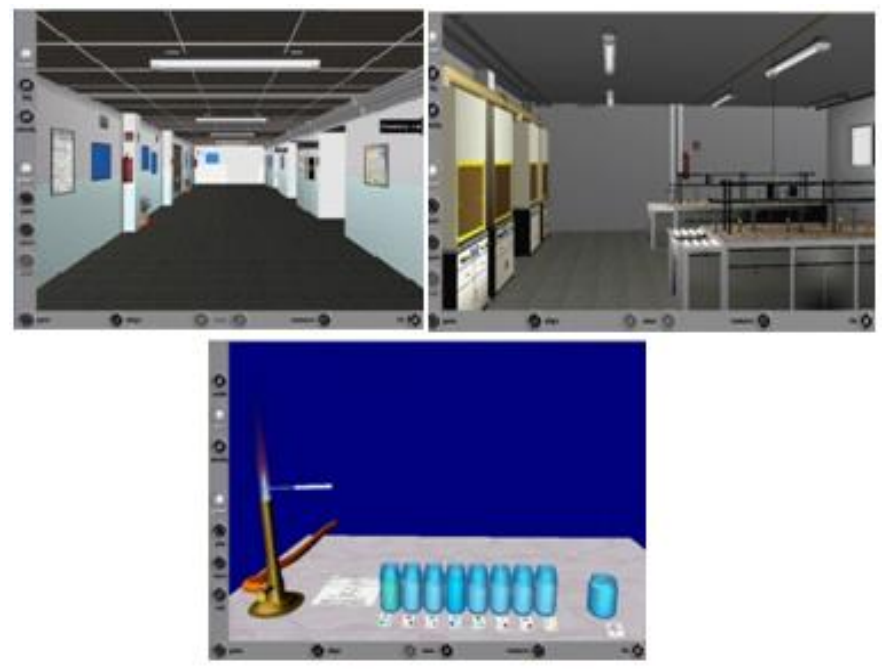

Fig. 5. The main hall of VMSLab-G and an experimentation using flame spectroscopy experiment [40]

\section{PROPOSAL}

By introducing AR in eMouss@ide system, the authors ensure the existence of the practical activity part.

\section{A. eMouss@ide System}

eMouss@ide[40], is a self-correcting adaptive learning system, offering learning scenarios based on the learners' learning styles and has the ability to self-correct based on traces and learners' feedback.

This system allows the teacher to index educational resources, to design, to edit and view learning scenarios as well as the learner can pass an MBTI test to identify his learning style, search for educational resources and learning scenarios according to his learning style, study the adapted courses to his profile, and evolve courses' adaptation offered at his learning mode.

The learning style detection of the learner is through the MBTI test, the learner passes from first inclusion in the platform.

\section{1) The MBTI test}

This test is a psychological test to determine the personality type of the user who passed the test, in this case it is the learner, allowing each individual to know his manner of perceiving the world and his way of acting; so it allows the learner to know his weaknesses, his potential and his 'energy sources'. The concept of psychological types proposed by Carl Jung [41] and then developed by Katherine Briggs and her daughter Isabel Myers into a practical self-assessment tool called the Myers-Briggs Type Indicator (MBTI). The MBTI has four categories and each category represents two opposite poles (Tab. 1).

TABLE I. The Dimensions Proposed by the MBti

\begin{tabular}{|l|l|l|}
\hline Dimensions & Preferences & \\
\hline Orientation of energy & E Extraversion & I Introversion \\
\hline Collection of information & S Sensing & N Intuition \\
\hline Decision making & T Thinking & F Feeling \\
\hline Mode of action & J Judging & P Perception \\
\hline
\end{tabular}

The psychological types are defined by a combination of four letters, these four letters used to designate 16 different psychological types.

Determining personality type is by selecting the letter from the dominant part of the dimensions (orientation of energy (E / I), Collection of information (S / N), Decision Making (T / F), Mode of action (J / P)).

\section{2) Limits of the eMouss@ide system}

The eMouss@ide is an adaptation system of courses for the learner's profile according to his personality style using the MBTI test and self-correct based on the learners' comments.

The theory remains inadequate in some matter, so learners need equipment to realize practical activity to complete the image built in the course.

eMouss@ide and most of the e-learning platforms are limited to the level of existence of experiments and practical activity management. 


\section{B.eMouss@ide's architecture:}

The platform eMouss@ide is composed of two parts Client and Server (Fig. 6); the client part contains two main users: the teacher has as role indexing educational resources and design scenarios. The second user is the learner how can take courses adapted to his personality after its determination by an MBTI test on the first registration of the learner in the system.

The two actors in the system have an appropriate interface depending on the users' tasks.

For the 'Server' part includes the warehouses, the database and the modules' part:

- Modules

- Module "Indexing educational resources" used by teachers to technically and pedagogically indexing the pedagogical resources used in the learning scenarios.

- Module "Scripting" used by teachers to create and index pedagogical scenarios.
- Module "pedagogical relationship" used by the system to connect the learning styles with teaching strategies.

- $\quad$ Module "Test learning style" used by the learners to determine their learning style.

- Module "Learning" used by learners to take courses.

- Module "Self-correction" used by the system to better adapt the course to the learner's learning style by using comments of learners at the end of the course.

- Warehouses and the database

- The learner's database contains the information relating to learners (name, level, learning style ...).

- The warehouse "Educational Resources ERs" contains educational resources indexed technically and pedagogically.

- The "scenarios" warehouse contains the scenarios indexed technically and pedagogically by the teacher.

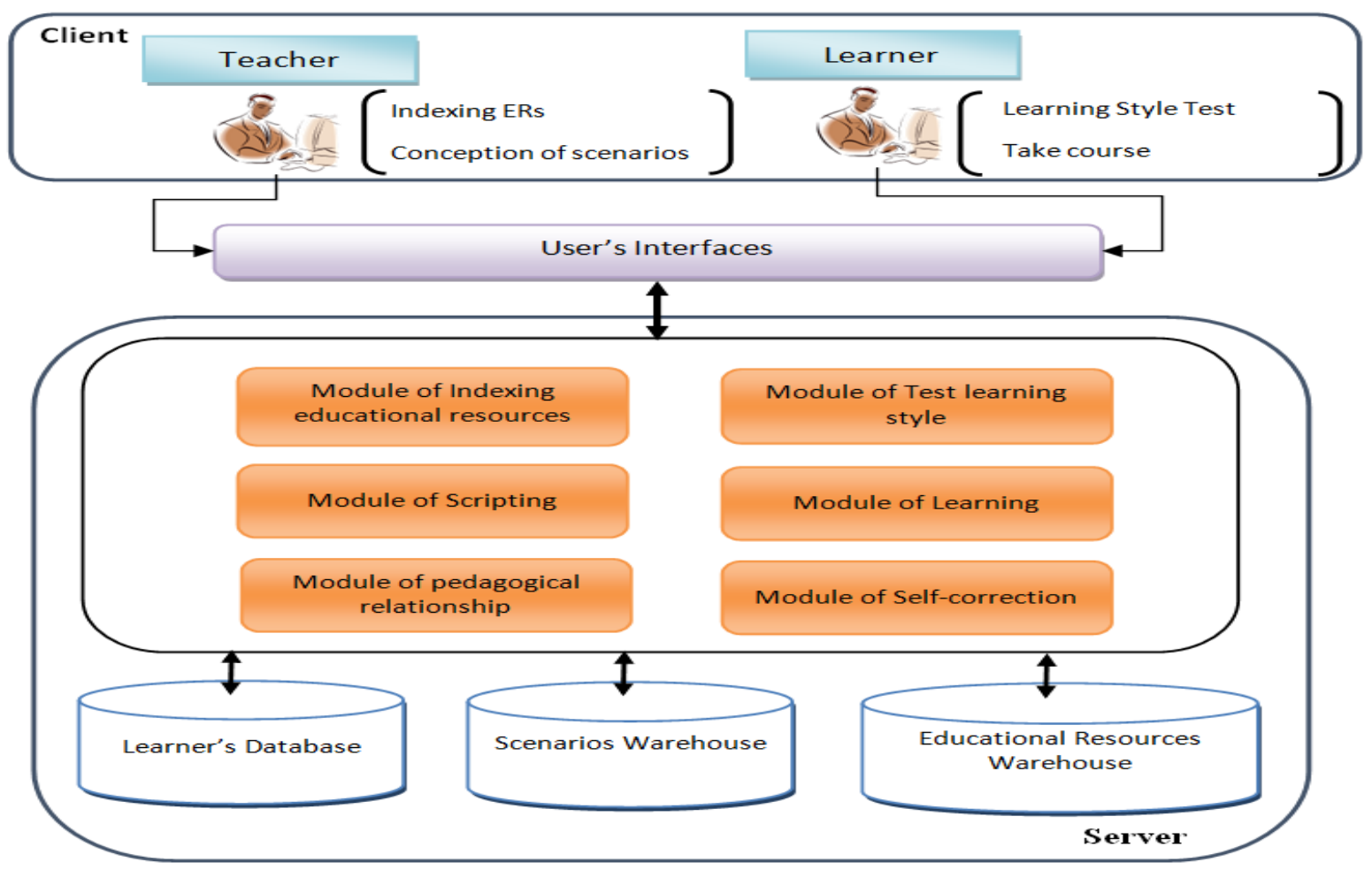

Fig. 6. General architecture of eMouss@ide [41]

\section{General Architecture of the modified system}

By using AR, the users can interact with virtual objects like if they are real objects in front of them.

The proposed upgrade to eMouss@ide platform ensures the distance practical activities using virtual reality and augmented reality, and manage the adaptation of those practical activities to the profile of each learner.
After the integration of the virtual practical activities solution, the eMouss@ide system architecture becomes like figured in Fig.7.

\section{General Architecture of the solution}

In the solution presented in Fig. 8, there are three actors: the designers, the teachers and the learners. The designers and the teachers are principle users in the design module; this module consists to create and to test the practical activities. The learners are principle user in the exploitation module, 
where the learners realize the saved practical activities in the "practical activities database" through the virtual environment
(Fig. 9). The communication between the system and the users pass through a web interface.

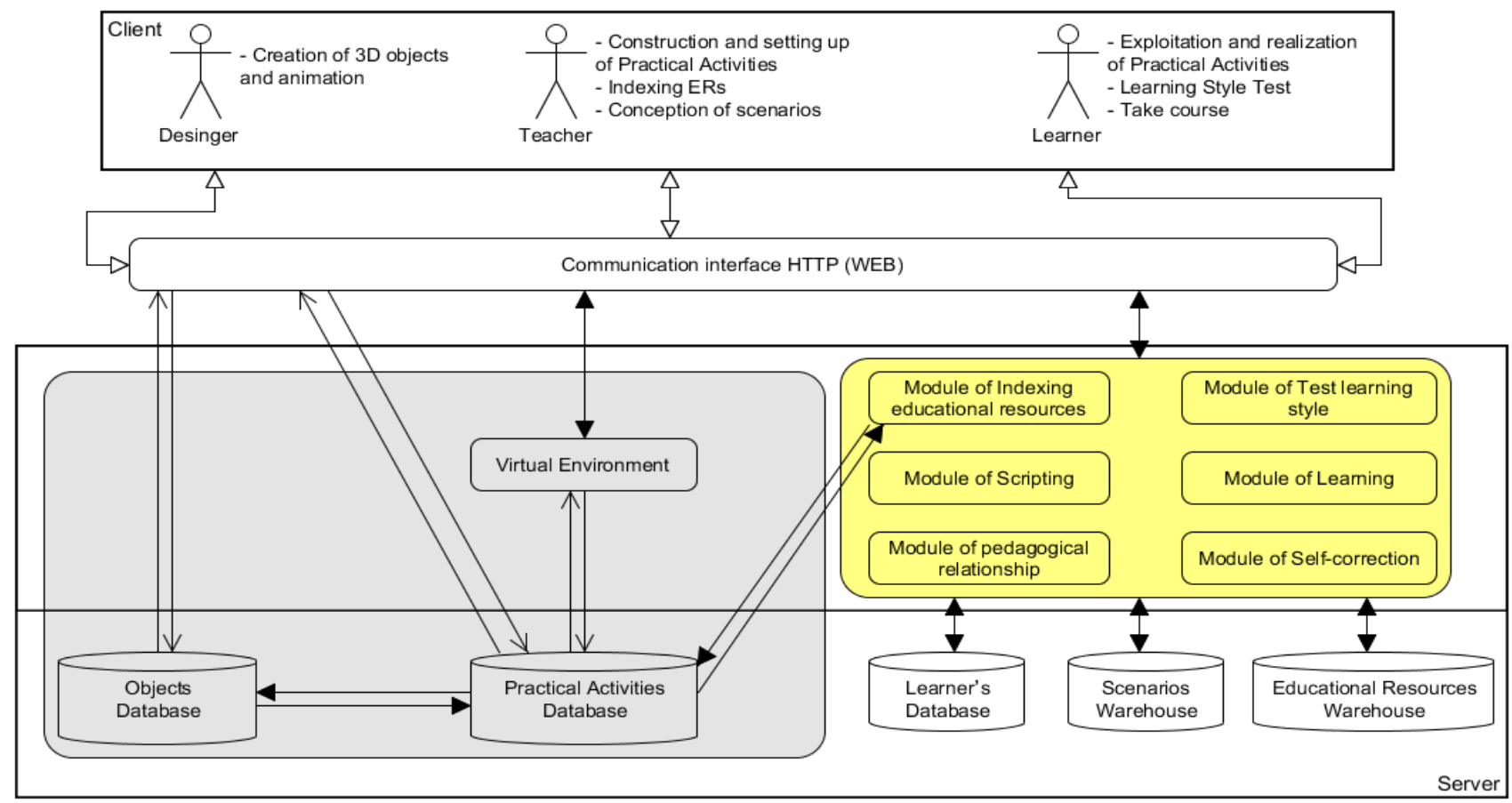

Fig. 7. General Architecture of the modified system

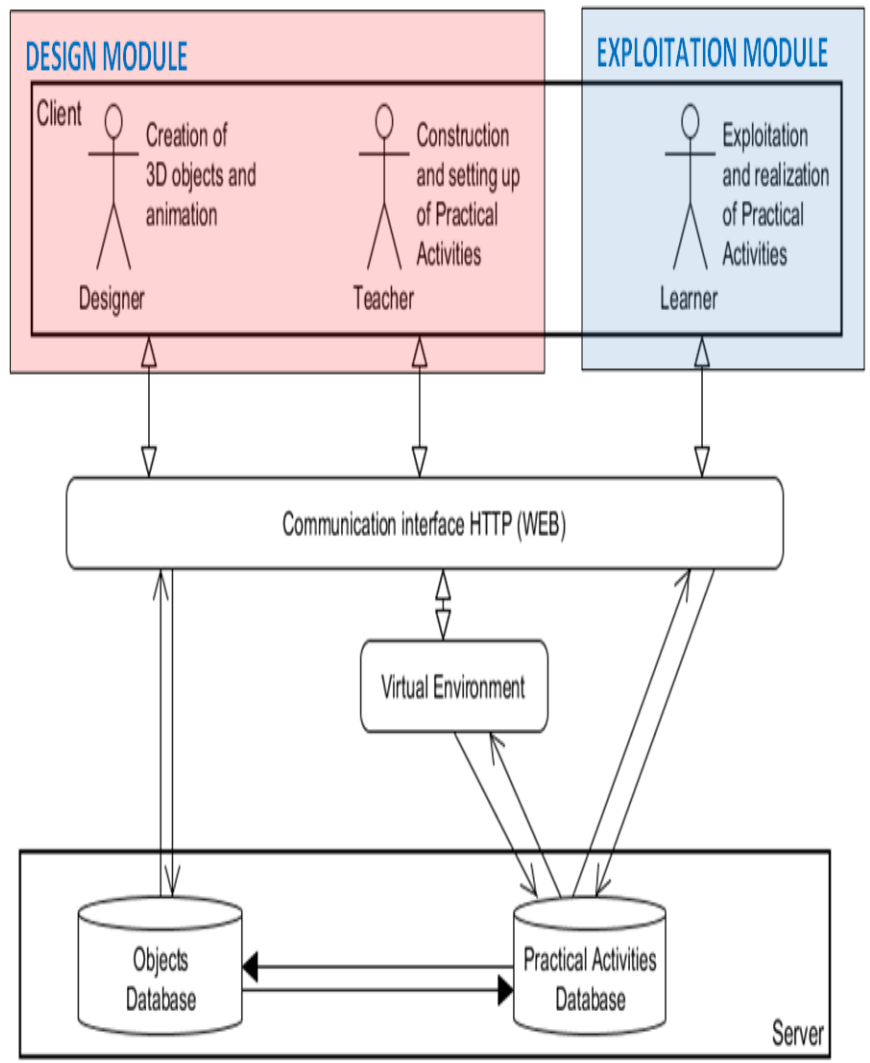

Fig. 8. General architecture of the solution

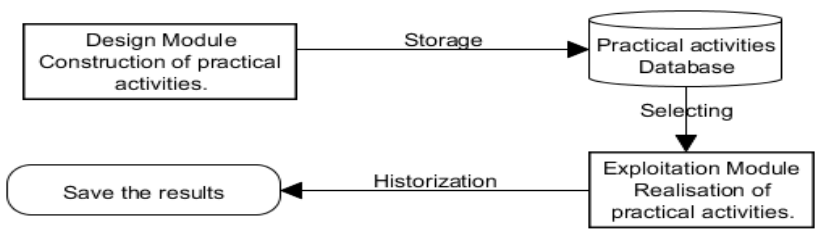

Fig. 9. General module of the system

\section{1) Practical Design Module}

In the design module, the teacher write a detailed description for the proposed practical activity and contacts the designer whore covers in his turn the description of the practical activity and verifies the existent objects in the database and creates the virtual equipment and there animation and storage them in the database (Fig. 10). The designer chooses the equipment to use in the practical activity from the virtual laboratory (Fig. 11) that imports the objects from "objects database". He prepares the practical activities and contacts the teacher to confirm the practical activity and storage it in "practical activities database". In addition, the teacher can modify the space of experimentation (e.g. initial positioning of the experimentation equipment) and tests the practical activity in the Virtual Environment before that the learners passes it. After that, he proceeds to create the quizzes to evaluate the learners' knowledge regarding this course. The other task consists to follow up the progress of learners based on participation in the session, delivered exercises also on realization and reports of practical activities and on the results of quizzes. Based on the results of monitoring learners, the 
teacher can contact the learners who appear weak to solve the problems they suffer.

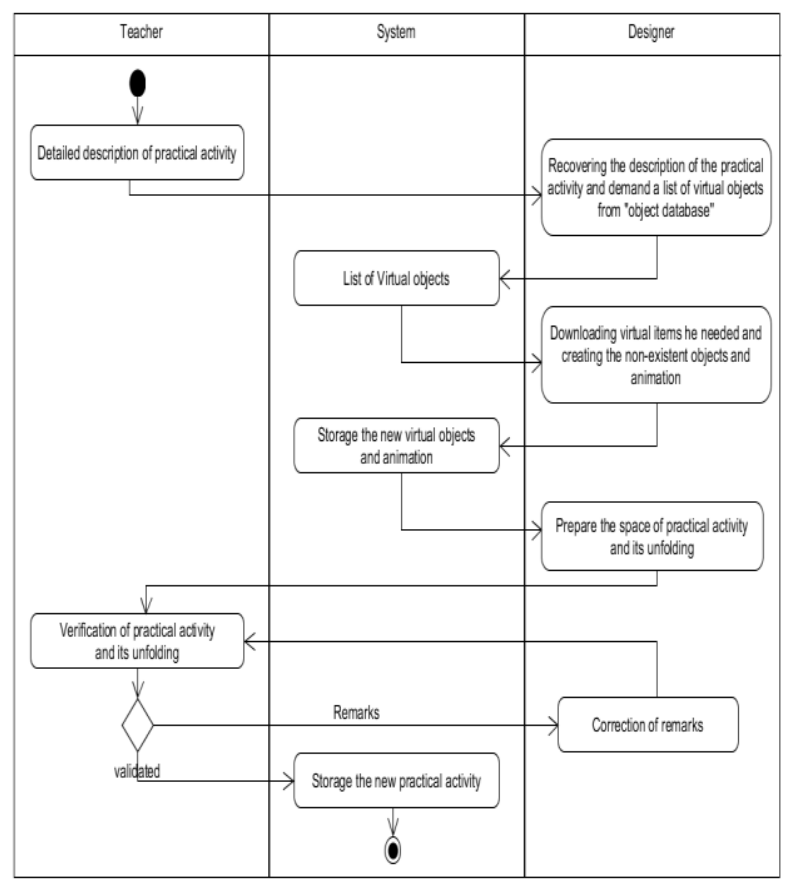

Fig. 10. Activity diagram of practical activities' creation

\section{Software:}

The Staging of the practical activity starts after that the designer receives the description of the practical activity and verifies the existent 3D object, by creating the non-existent virtual equipment and there animation using 3ds Max [42] or Cinema 4D [43], which are a 3D modeling software, it offers a complete solution for modeling, animation, simulation and rendering for game designers and film, as well as computer graphics and stores them in the database. After that, the designer proceeds to the screenwriting of the practical activity using Openspace3D software, which is a free and Open Source development platform for interactive real time $3 \mathrm{D}$ projects, it offers a solution creating a whole interactive 3D scene, with great graphical quality, without writing any code [44], that based on the principle of drag and drop of "Plugit".

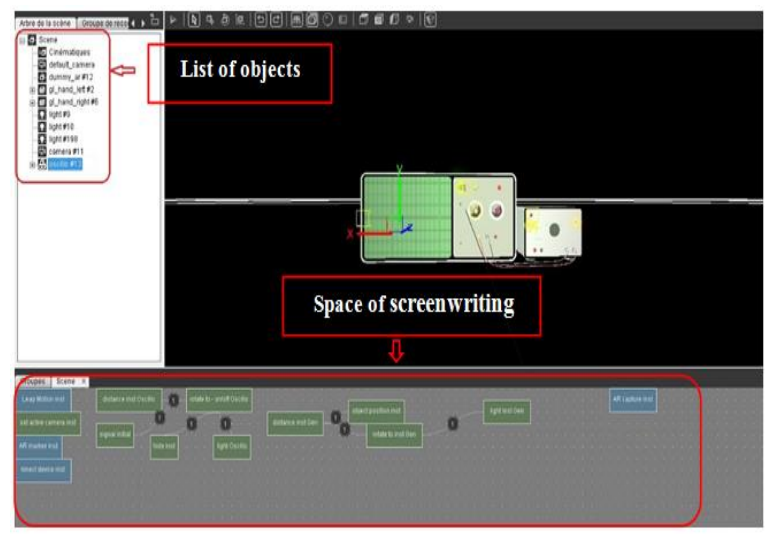

Fig. 11. Scene and list of equipment and scenario of interaction

\section{The creation phase:}

The practical works are created in OpenSpace3D. It used to create a virtual environment (or world) which the designer use as a scene to import the 3D objects from the "object database" and put them in the scene. Using a camera with its "Plugit" and combine it with the "Plugit" of augmented reality, the designer ensures the environment and the display of the virtual equipment. The designer have to make sure of the user's (the learner or the teacher) interaction with virtual environment, to supply it the designer and the other users must use a leap motion that help to detect the hand gesture. Therefore, the designer use the Leap motion "Plugit" and configures the set of hand gesture e.g. the punch to select and take the objects, the palm (open hand) to release the selected object, the index finger to click on a button.

\section{2) Exploitation Module}

The registered learner, have access to courses according to his formation and his level of education. Therefore, he can consult courses adapted to his profile and ask for teacher's assistance any time he needs it. After he understood the course, the learner proceed to the proposed exercises to fix the concepts learned in the course. Then the learner passes to the practical activity part to better clarify the lesson. Therefore, the "Module of indexing Educational Resources" of the eMouss@ide system shows the existing practical activities depending on his profile and level. After that he chooses his practical activity, the platform prepares the virtual environment where the practical activity takes place and begins the realization then writes a report of the results obtained and delivers it to the teacher. At the end, the learner passes a quiz that contains questions about the course and practical activity and its results.

\section{a) working environment}

\section{Hardware:}

To do the practical activities the learner needs a computer to display the virtual environment, a camera to generate the augmented reality's space and a Leap Motion to ensure the learner hands' gestures.

\section{Software:}

After the validation of the practical activity between the teacher and the designer, the learner finds all the objects needed to practice the practical activity in the scene of Openspace3D. The learner realize his practical activities in Openspace3D in the "Player mode" which is a passive window that the learner don't have the privilege to modify anything in the screenwriting scene.

\section{b) Interaction modes}

There are three ways to ensure the interaction of the user with the virtual objects:

- The first way to interact with the virtual objects is by using markers which are the reference point between the reel space and the augmented space. They are predetermined physical object detectable with the camera when the application is running. E.g. As figured in Fig. 12(a) a blue box present the marker of the virtual device and on the user's finger a blue sticker after running the application the camera detects 
the markers and converts them to virtual objects (Fig. 12-b). The interaction using markers make the precision of the virtual objects' location in the space easier but still limited to the configuration of the marker, the user needs to take a marker all the time in his hand to select an object, to do another action he needs to change the marker.

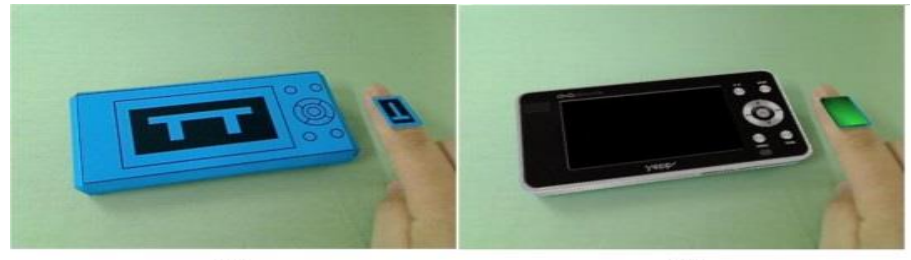

(a)

(b)

Fig. 12. Interaction using markers [45]

- Second way, the chosen one in this solution, is using a Leap motion, that contains sensors and detects the user's hands and there gestures. The interaction with the virtual objects in the augmented space is done using a virtual hand that appears when the user's hand detected and copies all the gestures of real hand. It provides seamless interaction in AR environments so the user can interact (select, take,...) with the virtual objects (Fig. 13a,b). The interaction is markerless and the configuration of the hand gestures is easier that makes the virtual objects' manipulation (catching, taking, turning, ...) much fluid. Therefore, this way needs sensors (Leap motion) that's mean some additional costs.

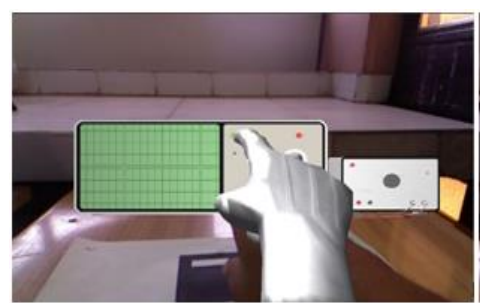

(a)

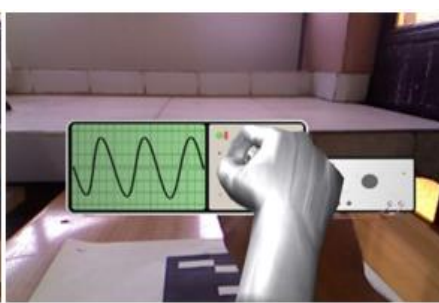

(b)
Fig. 13. a- User detection and apparition of experimentation tools b- Interaction with the oscilloscope and the generator

- The third way is using hand position in $3 \mathrm{D}$ environment by Stereo Camera [46]. The human hand is detected from input video image by use of the skin color model and image segmentation used in Chun's approach [47]. In the second phase, the 3D positions of the hand such as fingertip, the center of the palm and the center of the marker are evaluated using disparity map of the stereo-vision. In the third phase, the user can interact with a virtual object by detecting collision between the human hand and the object.

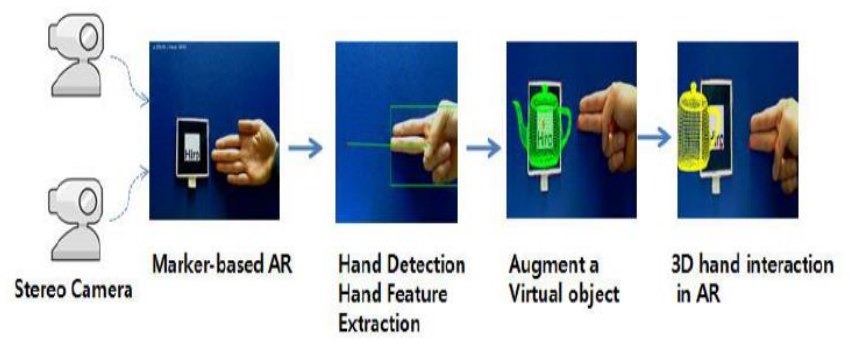

Fig. 14. Natural hand interaction[46]

\section{c) Procedure}

The learner starts by downloading the practical activity's instruction, reads it and he can ask for assistance help. Next, the learner begins the practical activity by following the instructions and takes notes to write a report. At the end, the learner saves the report and submits it to the teacher (Fig. 15).

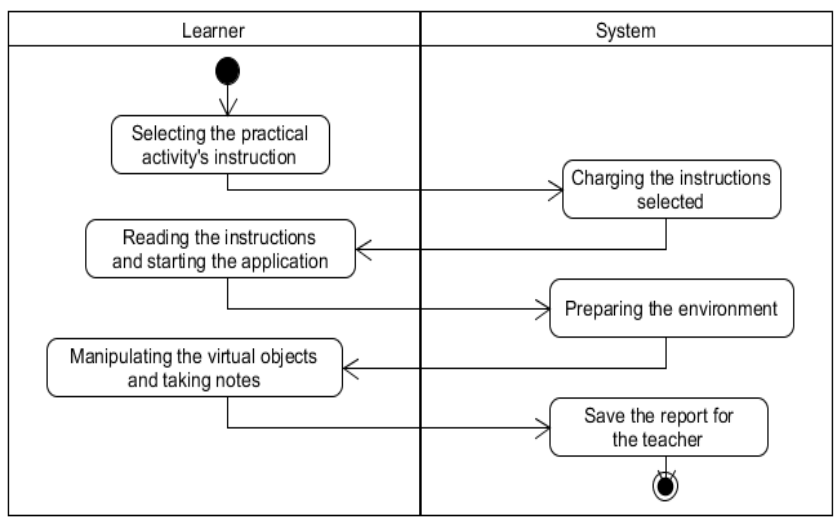

Fig. 15. Activity diagram of the practical activities' procedure

\section{EXPERIMENTATION}

\section{A. Protocol}

\section{1) Population}

The objective of this research is to measure the effect of the use of the MR in the VLE. To do this, it was proposed to a group of 10 students with different learning styles a scenario of practical activity using a virtual oscilloscope. It is noteworthy that none of the learners had any experience with this learning environment.

\section{2) Sequencing of the practical activity}

The execution of the experiment is done individually with each learner has a computer with the virtual environment, a camera and Leap motion connected to the computer. This practical activity named activity 1 as divided into 2 parts. The first part is an introduction to "Oscilloscope" and the second part is to experiment by taking measurements and render the generator voltage. Before launching the practical activity, the learner downloads the instruction manual detailing the required task. They had an unlimited access to the system (Fig.16).

At the beginning, the activity space was empty. Upon the detection of a user, the virtual oscilloscope appeared in the activity environment (Fig. 13a) where the learner started the first phase of the practical activity and began to recognize the elements of the oscilloscope by selecting any element to see its description. For example, if the learner had selected the setting button, it will display all information about this potentiometer. The same thing would happen for various buttons and keys on the oscilloscope. Here, the learner can repeat, as many times as he wants until he understands all the different components and their functions.

For the second part of this practical activity, the learner must manipulate and interact with various buttons of the oscilloscope and the generator in order to make the required measurements. The learner started by connecting the generator 
with the oscilloscope using cable (Fig. 13b), then he turned on the generator and the oscilloscope and proceeded to adjust the position of the signal to make it in the center of the screen. After that, he began to vary the voltage of the signal generator and observed the changes in the oscilloscope screen and started taking the measurements for report writing that had to be saved and submitted (Fig. 16).

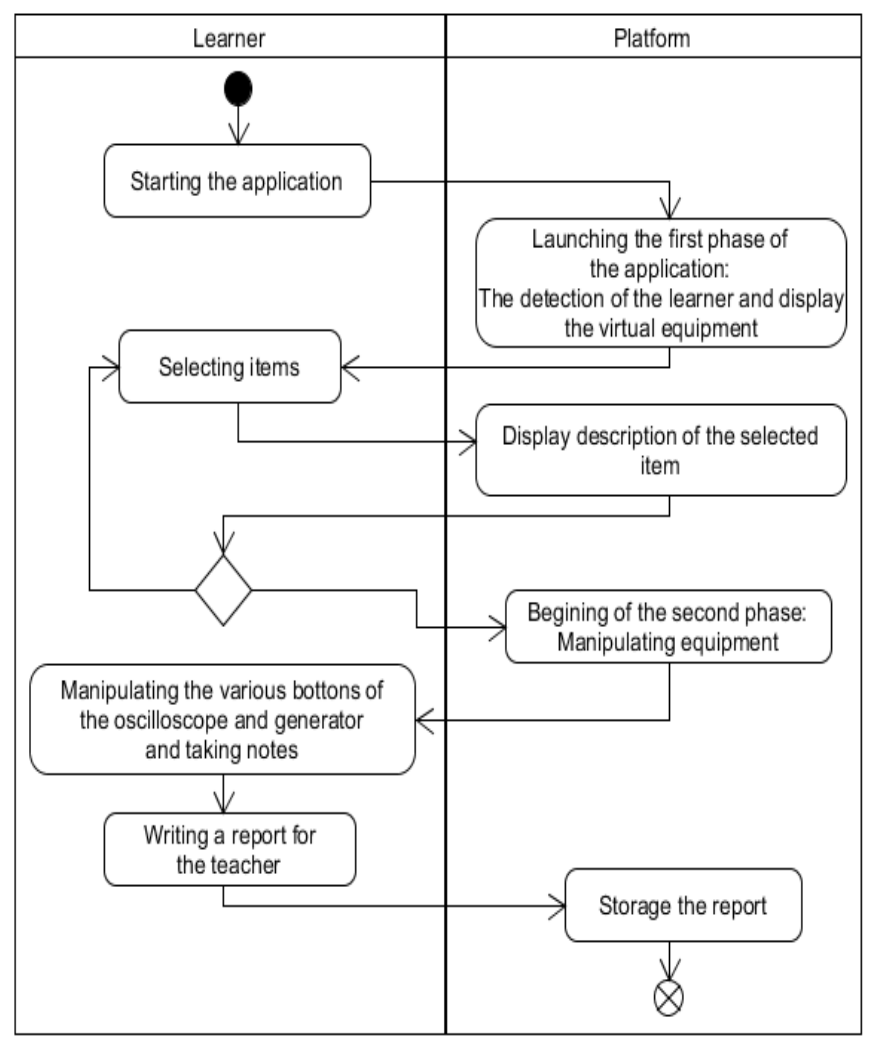

Fig. 16. Activity diagram of first activity's proceeding

\section{3) Collected data}

Once the learners complete the experiment, the behavioral data are collected: report of the activity, time of realization of the experiment, the number of requests for assistance and help, number of consultation of instructions and number of errors (when the learner does not select the right element to perform an action).

\section{B. Result}

\section{1) Report of the activity}

The report delivered by the learners has two parts: Questions section on the components of the oscilloscope (the first part of the practical activity), second part the measurements and calculations done during the experiment. After correcting the reports, $100 \%$ of learners validated the first part of the activity, which was a questionnaire containing inquiries about the components of the device and its operation. Same for the second part of the activity $100 \%$ of the learners were able to complete the experimentation and realize the required calculations.

\section{2) Time of realization}

Time of realization of the experiment varied from one learner to another, analytical comparisons indicate that the procedure duration for realization is significantly shorter when the learner requires less the assistance of the technician or the teacher and doesn't opt to the utilization or that of practical activity instructions and of course doesn't make many mistakes.

\section{3) Number of requests for assistance}

Number of requests for assistance or help varies from one student to another; analytical comparisons indicate that the number of request for assistance depends on comprehension of the learner to the new concept of the experimentation and the manipulation of tools and to the tasks to realize.

\section{4) Number of consultation of instructions}

This number varies from one learner to another due to the lack of student's concentration during the first reading, which influence the global time needed for the experimentation achievement.

\section{5) Number of errors}

The errors are classified into two categories: the first one, regroup the cases where learners select the wrong element in the machine to execute an action. The second one, covers the problems caused by the inability of the camera and the leap motion to detect the right gestural made by the learner.

\section{6) Detailled results}

The Tab. shows the students' result including the score of the quiz, the realization of the experimentation, the timing spent in the experimentation, the number of errors, the number of help request and the number of instruction's consultation. In general, all the students passed the practical activity and answered the quiz and the general score mean was $100 \%$ and $97 \%$, respectively.

First of all, the first question is about the organization and clearness of the experimentations in the platform, as a result, the students' satisfaction was 4.7 (very good). This result highlights the importance of the organization and the display of the experimentation, so it is easy for the learner to find the experimentation that he wants. For the evaluation of the Q2, the students have been very positive, by a score mean of 4.3, that the guidelines are appropriate. In addition, the students strongly agreed (with a score mean of 4.2) that the system improves the personal effort (Q3).Furthermore, the students were satisfied about the system (Q4) and the high score mean 4.4 proved that. Same for the students' need for this system (Q5), the majority choose that they need the system (score mean 4.6). Beside for the comparison between this system and the traditional system (Q6), the students considered that this system is very good by a mean score 4.1 .

As a summary, most of the students agreed that this system is able to meet the learning and teaching objective and specially the practical activity part. Furthermore, all the students agreed that this system is an effective tool for learning and teaching domains that need a practical activity part. This is because all the participants' students have validated the exam by a score mean of $97 \%$ (Tab.2). 
TABLE II. RESULTS OF STUDENTS

\begin{tabular}{|c|c|c|c|c|c|c|}
\hline \multirow[b]{2}{*}{ Learners } & \multicolumn{2}{|c|}{ Reports } & \multirow{2}{*}{$\begin{array}{l}\text { Time of } \\
\text { realization } \\
(\mathrm{sec})\end{array}$} & \multirow{2}{*}{$\begin{array}{l}\text { Number of } \\
\text { requests for } \\
\text { assistance }\end{array}$} & \multirow{2}{*}{$\begin{array}{l}\text { Number of } \\
\text { consultation of } \\
\text { instructions }\end{array}$} & \multirow{2}{*}{$\begin{array}{l}\text { Number of } \\
\text { errors }\end{array}$} \\
\hline & Quiz & $\begin{array}{l}\text { Realization of } \\
\text { experimentation }\end{array}$ & & & & \\
\hline Learner1 & $100 \%$ & $100 \%$ & 453 & 3 & 4 & 4 \\
\hline Learner2 & $100 \%$ & $100 \%$ & 498 & 3 & 4 & 7 \\
\hline Learner3 & $100 \%$ & $100 \%$ & 486 & 3 & 4 & 5 \\
\hline Learner4 & $100 \%$ & $100 \%$ & 587 & 3 & 4 & 5 \\
\hline Learner5 & $100 \%$ & $100 \%$ & 610 & 4 & 3 & 4 \\
\hline Learner6 & $80 \%$ & $100 \%$ & 658 & 5 & 5 & 6 \\
\hline Learner7 & $90 \%$ & $100 \%$ & 672 & 5 & 5 & 6 \\
\hline Learner8 & $100 \%$ & $100 \%$ & 521 & 4 & 4 & 3 \\
\hline Learner9 & $100 \%$ & $100 \%$ & 324 & 4 & 4 & 5 \\
\hline Learner10 & $100 \%$ & $100 \%$ & 395 & 3 & 4 & 6 \\
\hline $\begin{array}{l}\text { TOTAL (score } \\
\text { mean) }\end{array}$ & $97 \%$ & $100 \%$ & $\begin{array}{l}5204 \\
(520,4) \\
\end{array}$ & $\begin{array}{l}37 \\
(3,7)\end{array}$ & $\begin{array}{l}41 \\
(4,1)\end{array}$ & $\begin{array}{l}51 \\
(5,1)\end{array}$ \\
\hline
\end{tabular}

TABLE III. RESULTSOOF QUESTIONNAIRE ANALYSIS

\begin{tabular}{|c|c|c|c|c|c|c|c|}
\hline Topic & $\begin{array}{l}\text { Poor } \\
\text { (1) }\end{array}$ & Fair (2) & $\begin{array}{l}\text { Good } \\
\text { (3) }\end{array}$ & $\begin{array}{l}\text { Very } \\
\text { good (4) }\end{array}$ & Excellent (5) & $\begin{array}{l}\text { Score Mean } \\
\bar{X}=\frac{\sum_{i=1}^{n} x_{i} f_{i}}{n}\end{array}$ & $\begin{array}{l}\text { Standard deviation } \\
\sigma=\sqrt{\frac{\sum_{i=1}^{n}\left(x_{i}-\bar{X}\right)^{2} f i}{n}}\end{array}$ \\
\hline $\begin{array}{l}\text { Q1. The experiments are } \\
\text { clear and organized }\end{array}$ & 0 & 0 & 0 & 3 & 7 & 4.7 & 0.597 \\
\hline $\begin{array}{l}\text { Q2. The guidelines are } \\
\text { appropriate }\end{array}$ & 0 & 0 & 2 & 3 & 5 & 4.3 & 0,781 \\
\hline $\begin{array}{l}\text { Q3. The system improves } \\
\text { the personal effort }\end{array}$ & 0 & 0 & 2 & 4 & 4 & 4.2 & 0.748 \\
\hline $\begin{array}{l}\text { Q4. Overall reaction to the } \\
\text { described product }\end{array}$ & 0 & 0 & 1 & 4 & 5 & 4.4 & 0.663 \\
\hline $\begin{array}{l}\text { Q5. Your need for this } \\
\text { system }\end{array}$ & 0 & 0 & 0 & 4 & 6 & 4.6 & 0.489 \\
\hline $\begin{array}{l}\text { Q6. This system comparing } \\
\text { to the traditional system }\end{array}$ & 0 & 0 & 3 & 3 & 4 & 4.1 & 0.86 \\
\hline
\end{tabular}

\section{CONCLUSION AND FUTURE WORKS}

In this paper, the authors have presented a solution for the lack of practical activities in the E-learning platform without using remote control of real equipment. This solution was introduced in the existing adaptive learning system eMouss@ide and can be integrated in other learning systems.

The teacher presents a detailed description on the practical activity, including equipment needs and the functional of each of the equipment to the designer who supports the creation of the environment of the practical activity and ensures the interaction between the user (teacher or learner) and the augmented world. By using AR technology and Leap motion, the learner can get an interaction with virtual objects and can realize the practical activities, which reduces the risks of overload and failure of materials.

Thus, for the future work, we will try to eliminate the Leap motion and any other type of sensors to ensure the interaction with the AR's objects. The determination of user hand's gestures will be detected by using a just a camera so the learner just needs his computer and a simple webcam without any other additional costs. Also we will try to implement this solution as module of practical activity in other E-learning system and platform.

\section{REFERENCES}

[1] P. Dillenbourg, D. K. Schneider, and P. Synteta, "Virtual learning environments," in 3rd Hellenic Conference "Information \& Communication Technologies in Education," 2002, pp. 3-18.
[2] T. Haertel and I. Jahnke, "Kreativitätsförderung in der Hochschullehre: ein 6-Stufen-Modell für alle Fächer?!," Zeitschrift für Hochschulentwicklung, vol. 6, pp. 238-245, 2011.

[3] D. May, C. Terkowsky, T. Haertel, and C. Pleul, "Using E-Portfolios to support experiential learning and open the use of tele-operated laboratories for mobile devices," in 2012 9th International Conference on Remote Engineering and Virtual Instrumentation, REV 2012, 2012.

[4] C. Terkowsky and T. Haertel, "Where have all the inventors gone? Fostering creativity in engineering education with remote lab learning environments," in IEEE Global Engineering Education Conference, EDUCON, 2013, pp. 345-351.

[5] H. G. Bruchmüller, Labordidaktik für $\{$ Hochschulen $<p>$ Eine $\}$ Einführung zum Praxisorientierten \{Projekt-Labor\}. Leuchtturm Verlag, 2001 .

[6] C. Terkowsky, C. Pleul, A. E. Tekkaya, and I. Jahnke, "PeTEX -Platform for eLearning and Telemetric Experimentation," in Praxiseinblicke -- Forschendes Lernen in den Ingenieurwissenschaften, vol. 1, 2011, pp. 28-31.

[7] L. Arnaud, M. Cécile, and P. Patrick, "Télé-TP : Premiers pas vers une modélisation," Technol. l'Information la Commun. dans les Enseign. d'ingénieurs dans l'industrie, pp. 203-221, 2002.

[8] J. Carmigniani, B. Furht, M. Anisetti, P. Ceravolo, E. Damiani, and M. Ivkovic, "Augmented reality technologies, systems and applications," Multimed. Tools Appl., vol. 51, pp. 341-377, 2011.

[9] Z. Pan, A. D. Cheok, H. Yang, J. Zhu, and J. Shi, "Virtual reality and mixed reality for virtual learning environments," Computers \& Graphics, vol. 30. pp. 20-28, 2006.

[10] E. W. T. Ngai, J. K. L. Poon, and Y. H. C. Chan, "Empirical examination of the adoption of WebCT using TAM," Comput. Educ., vol. 48, pp. 250-267, 2007. 
[11] E. A. Wehrwein, H. L. Lujan, and S. E. DiCarlo, "Gender differences in learning style preferences among undergraduate physiology students.," Adv. Physiol. Educ., vol. 31, pp. 153-157, 2007.

[12] E. Kanninen, "Learning styles and e-learning," 2008.

[13] P. Brusilovsky, "Adaptive hypermedia," User Model. User-adapt. Interact., vol. 11, pp. 87-110, 2001.

[14] M. Athanasios, K. Theodoros, and B. Kostas, "Design \& Development of a Dynamic Hypermedia Educational System," J. Inf. Technol. Impact, vol. 2, no. 3, pp. 105-116, 2001.

[15] N. Henze, "Adaptive Hyperbooks: Adaptation for Project-Based Learning Resources," Hannover, Germany, 2000.

[16] P. Brusilovsky, "Methods and techniques of adaptive hypermedia," User Modeling and User-Adapted Interaction, vol. 6. pp. 87-129, 1996.

[17] P. Brusilovsky, "Adaptive Educational Hypermedia," in Proceeding of Tenth International PEG Conference, 2001, pp. 8-12.

[18] P. Brusilovsky, J. Eklund, and E. Schwarz, "Web-based education for all: A tool for developing adaptive courseware," in Computer Networks and ISDN Systems, 1998, pp. 291-300.

[19] P. Brusilovsky, E. Schwarz, and G. Weber, "ELM-ART: An Intelligent Tutoring System on World Wide Web," in Intelligent Tutoring Systems, 1996, pp. 261-269.

[20] P. M. E. De Bra, "Teaching hypertext and hypermedia through the web," J. Univers. Comput. Sci., vol. 2, pp. 797-804, 1996.

[21] R. M. Carro, E. Pulido, and P. Rodríguez, "TANGOW: Task-based Adaptive learNer Guidance On the WWW," Second Work. Adapt. Syst. User Model. World Wide Web, pp. 49-57, 1999.

[22] P. De Bra and L. Calvi, "AHA! An open Adaptive Hypermedia Architecture," New Review of Hypermedia and Multimedia, vol. 4. pp. 115-139, 1998.

[23] K. A. Papanikolaou, M. Grigoriadou, H. Kornilakis, and G. D. Magoulas, "Personalizing the interaction in a web-based educational hypermedia system: The case of INSPIRE," User Model. User-Adapted Interact., vol. 13, pp. 213-267, 2003.

[24] E. Triantafillou, A. Pomportsis, and S. Demetriadis, "The design and the formative evaluation of an adaptive educational system based on cognitive styles," Computers \& Education, vol. 41. pp. 87-103, 2003.

[25] A. Kumar, R. Pakala, and R. K. Ragade, "The Virtual Learning Environment system," in Frontiers in Education Conference, 1998. FIE '98. 28th Annual, 1998, vol. 2, pp. 711-716 vol.2.

[26] E. Klopfer and K. Squire, "Environmental detectives-the development of an augmented reality platform for environmental simulations," Educ. Technol. Res. Dev., vol. 56, pp. 203-228, 2008.

[27] P. Milgram, H. Takemura, A. Utsumi, and F. Kishino, "Mixed Reality ( MR ) Reality-Virtuality ( RV ) Continuum," Syst. Res., vol. 2351, pp. 282-292, 1994.

[28] D. W. F. Van Krevelen and R. Poelman, "A survey of augmented reality technologies, applications and limitations," ... J. Virtual Real., vol. 9, pp. 1-20, 2010.

[29] R. Azuma and R. Azuma, "A survey of augmented reality," Presence Teleoperators Virtual Environ., vol. 6, pp. 355-385, 1997.
[30] G. Burdea and P. Coiffet, "Virtual reality technology," in Presence: Teleoperators \& Virtual Environments, 2003, vol. 12, pp. 663-664.

[31] K. Bokyung, "Investigation on the relationships among media characteristics, presence, flow, and learning effects in augmented reality based learning," in Multimedia and E-Content Trends: Implications for Academia, 2009, pp. 21-37.

[32] M. Dunleavy, C. Dede, and R. Mitchell, "Affordances and limitations of immersive participatory augmented reality simulations for teaching and learning,” J. Sci. Educ. Technol., vol. 18, pp. 7-22, 2009.

[33] A. B. Craig, Understanding Augmented Reality. 2013.

[34] G. Chang, P. Morreale, and P. Medicherla, "Applications of augmented reality systems in education," Technol. Teach. Educ., vol. 2010, pp. 1380-1385, 2010.

[35] M. Billinghurst, H. Kato, and I. Poupyrev, "The MagicBook - Moving seamlessly between reality and virtuality," IEEE Comput. Graph. Appl., vol. 21, pp. 6-8, 2001.

[36] D. A. Kolb, "Experiential learning: Experience as the source of learning and development," J. Organ. Behav., vol. 8, pp. 359-360, 1984.

[37] M. E. Auer and A. Pester, "Toolkit for Distributes Online-Lab Kits," Adv. Remote Lab. e-learning Exp., vol. 6, pp. 285-296, 2007.

[38] O. Gervasi, A. Riganelli, L. Pacifici, and A. Laganà, "VMSLab-G: A virtual laboratory prototype for molecular science on the Grid," Futur. Gener. Comput. Syst., vol. 20, pp. 717-726, 2004.

[39] H. EL Kabtane, Y. Mourdi, M. EL Adnani, and M. Sadgal, "The integration of augmented reality in the virtual learning environment for practical activities," in Electrical and Information Technologies (ICEIT), 2015 International Conference on, 2015, pp. 363-368.

[40] A. Ben Bouna, "Vers un système d'enseignement à distance adaptatif aux styles d'apprentissage des apprenants," Cadi Ayyad faculté des sciences Semlalia, 2012.

[41] C. Jung, "Psychological Types: The collected works of CG Jung,(vol. 6)," Princet. Univ. Press. Princeton, NJ, USA (1921/ ..., 1971.

[42] AUTODESK, "3ds Max," 2015. [Online]. Available: http://www.autodesk.fr/products/3ds-max/overview. [Accessed: 09-Sep2015].

[43] maxon, "Cinema 4D," 2015. [Online]. Available: http://www.maxon.net/fr/products/cinema-4d-studio.html. [Accessed: 09-Sep-2015].

[44] I-maginer, “Openspace3D," 2015. [Online]. Available: http://www.openspace3d.com/. [Accessed: 09-Sep-2015].

[45] P. Hyungjun, J. Ho-Kyun, and P. Sang-Jin, "Tangible AR interaction based on fingertip touch using small-sized nonsquare markers," J. Comput. Des. Eng., vol. 1, no. 4, pp. 289-297.

[46] J. Chun and S. Lee, "A Vision-based 3D Hand Interaction for Markerbased AR,” Int. J. Multimed. Ubiquitous Eng., vol. 7, no. 3, pp. 51-58.

[47] J. Chun and S. Lee, "Dynamic Manipulation of a Virtual Object in Marker-less AR system Based on Both Human Hands," Trans. Internet Inf. Syst., vol. 4, no. 4, pp. 618-632, 2010. 